\title{
Automatic IoT Based Plant Monitoring and Watering System using Raspberry Pi
}

\author{
Anusha k ${ }^{\mathrm{a}}$, Dr. U B Mahadevaswamy ${ }^{\mathrm{b}}$ \\ ${ }^{a}$ PG Scholar, Department of Electronics and Communication Sri Jayachamarajendra College of Engineering, \\ Mysuru-570006, Karnataka, India \\ ${ }^{b}$ Associate Professor, Department of Electronics and Communication Sri Jayachamarajendra College of \\ Engineering, Mysuru-570006, Karnataka, India
}

Received: 28 July 2017; Accepted: 07 October 2018; Published: 08 November 2018

\begin{abstract}
The main objective of this proposed work is to develop an Embedded System for plant monitoring and watering system using Internet of Things, Raspberry Pi as Processor, and sensors for sensing environmental conditions. In this work, IoT concept is introduced to connect devices through Internet and facilitate information access by the users. The system can obtain accurate perception of Environmental information in agriculture field and then transmit the same to users. The system monitors different parameters like Temperature, Humidity, Soil Moisture and Intensity of light. IR sensor is fixed to check any external object entry into the field, in case of intruder detection buzzer will turn on for few seconds. The Motor fixed in the field operates both manually and automatically depending upon Moisture sensor results in soil. Motor automatically switches between on and off stage of pumping action. Results are observed either in web app and monitor.
\end{abstract}

Index Terms: Internet of Things, sensors, Raspberry Pi and motor.

(C) 2018 Published by MECS Publisher. Selection and/or peer review under responsibility of the Research Association of Modern Education and Computer Science.

\section{Introduction}

In India approximately $60 \%$ of citizens are depending on agriculture, annual income of citizens obtains from agriculture. In today's digital world many farmers are still using traditional methods in their field so; yield of plants is very less. Applying novel technology in the field will solve main issues in agriculture. IoT is one

* Corresponding author.

E-mail address: 
among the fastest growing technologies. The IoT concept is applicable to all fields like automation, industry, electrical, electronics, health care, tracking systems etc. In case of plant growth automation is necessary to monitor several environmental conditions. The Proposed system is based on monitoring and watering system for agriculture field based on Internet of Things which help the farmers to apply new modern methods, can increase their income with less manual work. Now a day's traditional agriculture is changing to a modern agriculture. Currently many agriculture applications are existed which became a business. Improvements in agriculture contribute to the national economic growth.

Automatic system can apply to all kinds of agriculture field. Internet of Things is a connection of physical things to operate devices with the help of Internet. IoT is the network connection of many electronic things. It enables to access any information with the help of electronic components. The proposed system mainly works on connecting Internet to main system in plant field, smart phones to check the result. The internet connected to device via smart phone which is acts as Wi-Fi to monitor and other devices to see results [16].

Raspberry Pi processor is a computer which can be used for all kinds of projects. It operates under Linux operating system. Python language is used to dump in processor. Processor operates at $3.3 \mathrm{~V}$, memory is $1 \mathrm{~GB}$ RAM. Raspberry Pi processor will be applicable for hobby project, real-time applications, and computer applications [17]. Many sensors are available to measure different environmental conditions. In proposed system sensors like temperature, humidity, IR, soil moisture and light sensor are fixed at plant field for monitoring the different environmental conditions. This sensor doesn't require more power supply and less cost [18].

Server based web application is developed. Application has two part script \& programming and coding. Application shows same result as monitored by sensors with the help of http protocol. Hyper text mark up language is used to code application. The backend language is java script. Results observed when login done with IP address in application. Along with results in web application monitor also continuously displaying result until system shut down. For monitor direct connection with board in case of laptop putty software has to be installed. More in speed of internet makes results observation within a fraction of seconds. Code mounted for server in flash method. Main aim of this work is to develop monitoring and watering system of agriculture to solve problems faced by farmers in India.

\section{Related Work}

In [1] Author discussed about concept developed for automated irrigation system to optimize use of water for agriculture crops. Soil moisture sensor was inserted to measure water content in soil. The system was tested in a sage crop field for 136 days. Web app was developed to see results.

In [2] Author proposed concept for intelligence and its application in agriculture to check current climatic change which makes the biological system more complicated and unpredictable.

In [3] Author proposed system for agriculture application, i.e. irrigation to save water. The test shows savings of $1500 \mathrm{ml}$ of water per day per tree. Interconnection of GSM/GPRS/Wi-Fi module, moisture sensor to Internet concentrated on protection and security like attacks of rodents or accessed by user takes place. Results observed graphically.

Paper [4] Author developed prototype for securing crop field from insects, or in grain stores. Each and every day data has been collected, web camera fixed in field capture information. Raspberry Pi processor used runs with python code.

[5] The Authors developed system for green house. Monitored valves in field were PH, temperature, soil moisture valves mounted on different areas.

In paper [6] Authors developed about web application for things in farming. They proposed some challenges and how to overcome from challenges.

In [7] Author discussed about what are the problems phased by farmers in India, how to overcome using their proposed system with the help of IoT concept, sensors and network MQTT protocol.

Paper [8] authors discussed about smart farming with sensors fixed at different locations. The results have 
been observed graphically.

In [9] Authors developed the system which was combination of embedded technology and web server for the surveillance of green house system; they mainly concentrated on software part of embedded technology.

In [10] Authors discussed about different sensors, microcontroller. This developed system was low power device. Remote control with wireless sensor network technology established, by saying can reduce manual work converts to automation remote system.

Paper [11] explains about Crop system with the help of IoT. The processor was ATmega18 with the interconnection of different sensors, result of this device done for wheat crop in Beijing.

In [12] authors developed system with the help of different sensors to monitor the environmental conditions in agriculture land, the IoT concept applied which includes microcontroller, the GSM module was established in the project, and results were observed in LCD screen and also in the graphical representation.

In [13] authors developed automatic irrigation model with the help of GSM- Bluetooth technology. Proposed system includes 8 bit-microcontroller, RS interfaces, and Bluetooth modules. The different sensors interfaced with the controller to check for various applications.

Paper [14] details about agriculture field monitoring system developed with the help of arm, GSM, Zigbee module. The device includes two parts transmitter and receiver. The result of the sensors was checked with the help of LCD screen. The water level sensor used to check water content in the well.

In [15] authors explained about wireless network topologies for remote monitoring in agriculture field. They demonstrated project with the help of qual net simulator, for the demonstration purpose the sensor results they shown in simulator.

Paper [16] explained about review of crop monitoring system. This mainly work on soil moisture content and leaf water content with the help of wireless sensor network, GSM with SMS based result. Along with soil moisture sensor, the soil PH sensor was inserted here the analog values has been converted to digital using ADC. The SMS send to the people to access result.

Following are the drawbacks of the existing system which the authors have learnt through literature survey.

- $\quad$ Not developed for all kind of farming.

- $\quad$ Safety and Security was less.

- $\quad$ Less number of sensors used.

- Memory of processor/controller was less.

\subsection{Problem Statement}

Improvement in the agriculture field needs lot of caring and use of digital concepts. Countries like India though the main source for citizens is agriculture they use an old traditional method which makes them earn less money, not able to solve family financial problems. Some of the instruments they can't fix due to huge amount so, in order to overcome these problems this system is developed and should be economical to the users.

\subsection{Motivation}

Agriculture system requires digital technology to solve big challenges. The automation, usage of sensors, a processor, new technologies and remote automation can solve any challenge. This made us to develop a device for plant monitoring and watering system continuously with the help of on growing technology Internet of Things.

\subsection{Objectives}

- $\quad$ To Design prototype for plant monitoring and watering system using Raspberry pi as processor and Internet of Things technology. 
- $\quad$ To develop web based Application for accessing result.

- $\quad$ To develop system for Real Time Application.

\section{Research method}

The proposed system includes both hardware and software. The block diagram main system interfaced with all components with processor is shown in the Fig.1. The hardware requirements are pointed.

- $\quad$ Raspberry pi(Model B 3.1)

- $\quad$ Temperature sensor(LM35), Humidity sensor

- Moisture sensor

- $\quad$ Light sensor

- $\quad$ IR sensor

- Relay and motor

- $\quad$ Server with data base and IoT enabled web based application

- $\quad$ Power supply

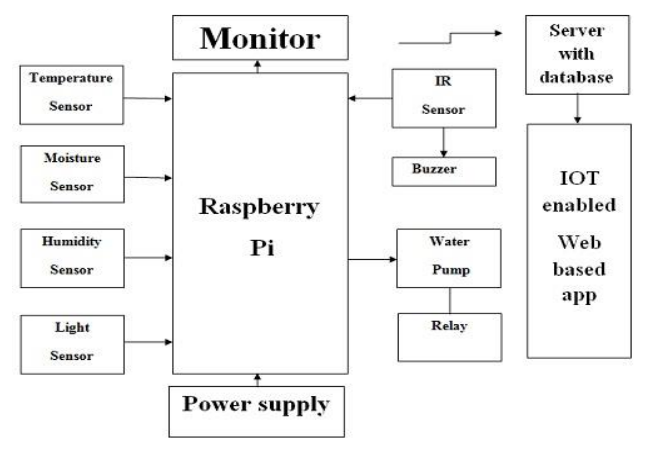

Fig.1. Block Diagram of Proposed System

The important components in the block diagram are explained separately with their model and features. To Raspberry Pi all the components are connected, code dumped in SD card inserted in processor.

Raspberry pi: Raspberry Pi model $3 \mathrm{i}$ B is shown in the figure 2. It is a computer which operates under UNIX operating system. It includes 4 USB ports, HDMA port, 40 GPIO pins, SD card slot, Arm 11. All hardware components are interfaced with this processor. It operates at the supply of $3.3 \mathrm{~V}$. After connecting all sensors to the processor it login using UNIX commands. The language used to code is in Python language which is dumped into the processor. It can be applicable to all kinds of projects.

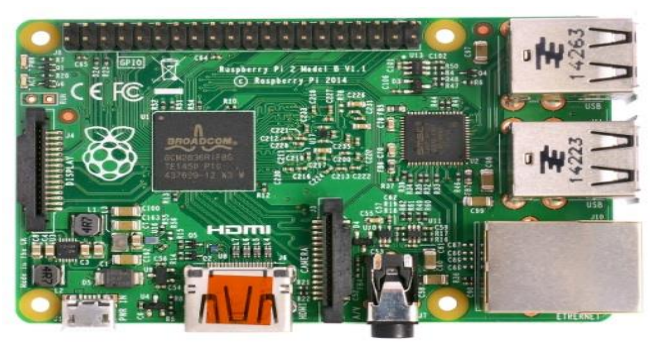

Fig.2. Image of Raspberry Pi 
Temperature and Humidity sensor: Temperature and humidity sensors monitor environmental conditions in the crop field every day. Temperature sensor operates when the applied voltage increases. Similarly humidity sensor works by change in temperature in air and change in electrical current. The different types of humidity sensor are capacitive, thermal and resistive. In our project capacitive sensor is used. These sensors gives results in Analog farm which are converted to digital valve by the use of analog to digital converter using serial peripheral interface MCP3008. The sensors image is shown in the figure 3.

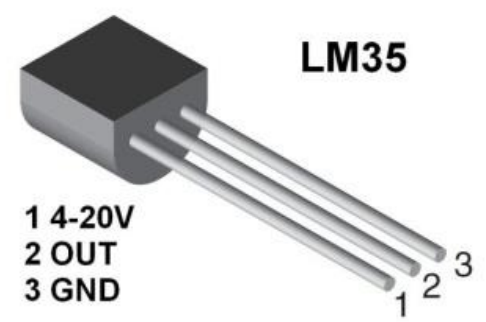

(a)

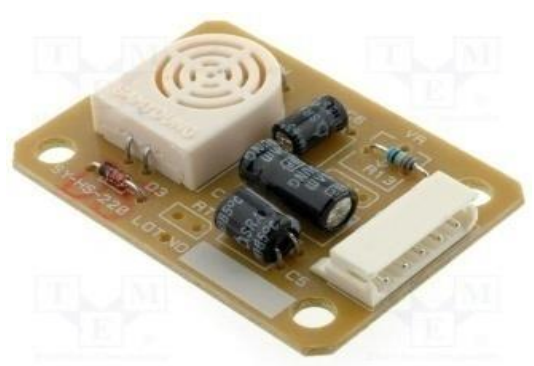

(b)

Fig.3. (a) Temperature sensor and (b) Humidity sensor.

IR Sensor:The Infrared sensor emits to sense aspects of the surroundings. In IR emitter is LED and the detector is photodiode hence it is called opto-coupler. It measures heat of the object and motion. In the proposed system IR sensor identifies the intruder entry, if yes then buzzer will on. It operates at $5 \mathrm{~V}$ supply. The model of ir sensor shown in the figure 4.

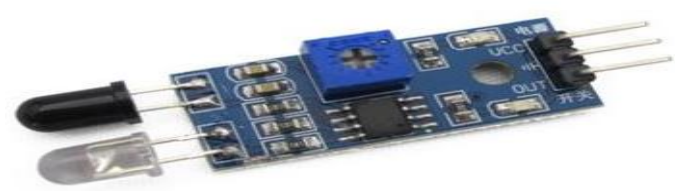

Fig.4. IR sensor.

Moisture sensor: Moisture sensor measure water content in the soil. This sensor reminds the user to water their plants and also monitors water content in the soil. It uses capacitance to measure dielectric permittivity of the medium. This creates applied voltage proportional to the dielectric permittivity. It operates at $5 \mathrm{~V}$. The image of sensor is shown in the figure 5. 


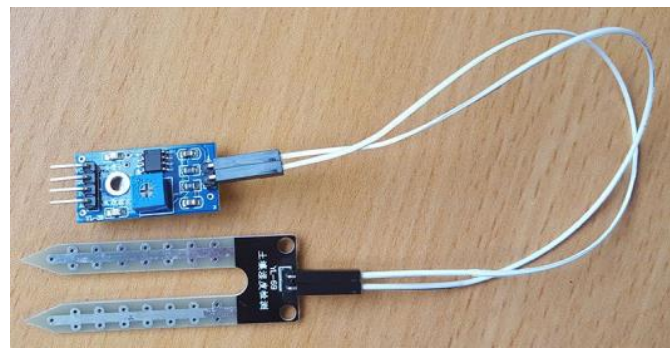

Fig.5. Moisture Sensor

The flow chart for implementing project is shown in the figure 6. The system includes two parts hardware and software, for Implementation both takes an important role. The chart gives software view of the protocol.

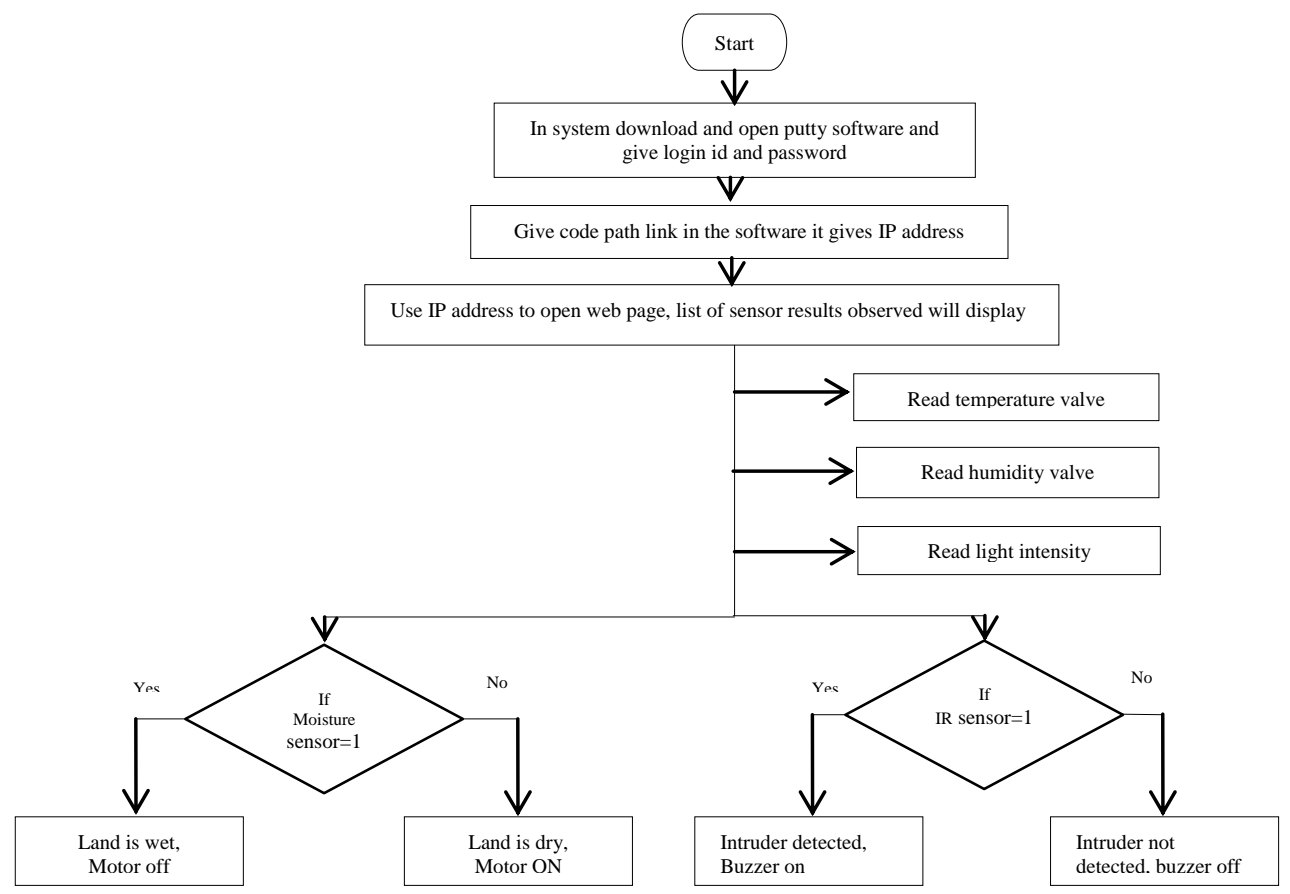

Fig.6. Flow Chart for sensor operation

The Raspberry Pi operates on Linux- noobs operating system. The operating system is dumped in SD card inserted in the processor. The python language is used for coding. After all hardware connection done power supply switch on, in the monitor terminal screen login has to take place to run the system.

\section{Results and Analysis}

The prototype of model is developed, which is kept in garden. The same prototype can also fit for agricultural applications based on which sensor required. Each sensor with its unique identity can access changes in the Environment continuously. The test scenario of prototype is shown in the figure 7. 


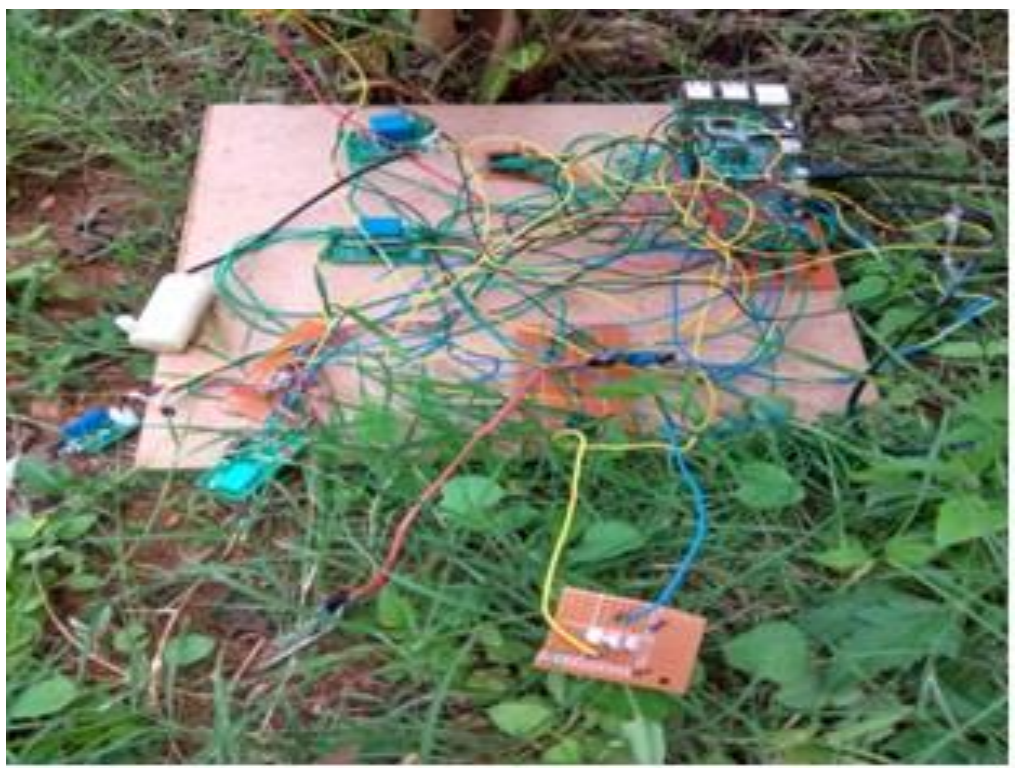

Fig.7. Hardware view of Main System in Plant Field

After installation switch on power, connect keyboard and mouse to the Raspberry Pi. Sensor captures information when login take place. Two times login has to take place for secured and safe communication. The image of login page in monitor is shown in the figure 8. In the page first make user as super user by giving command "sudo su". Later give command path to open script in Raspberry Pi computer monitor. Later take the generated IP address run in web application.
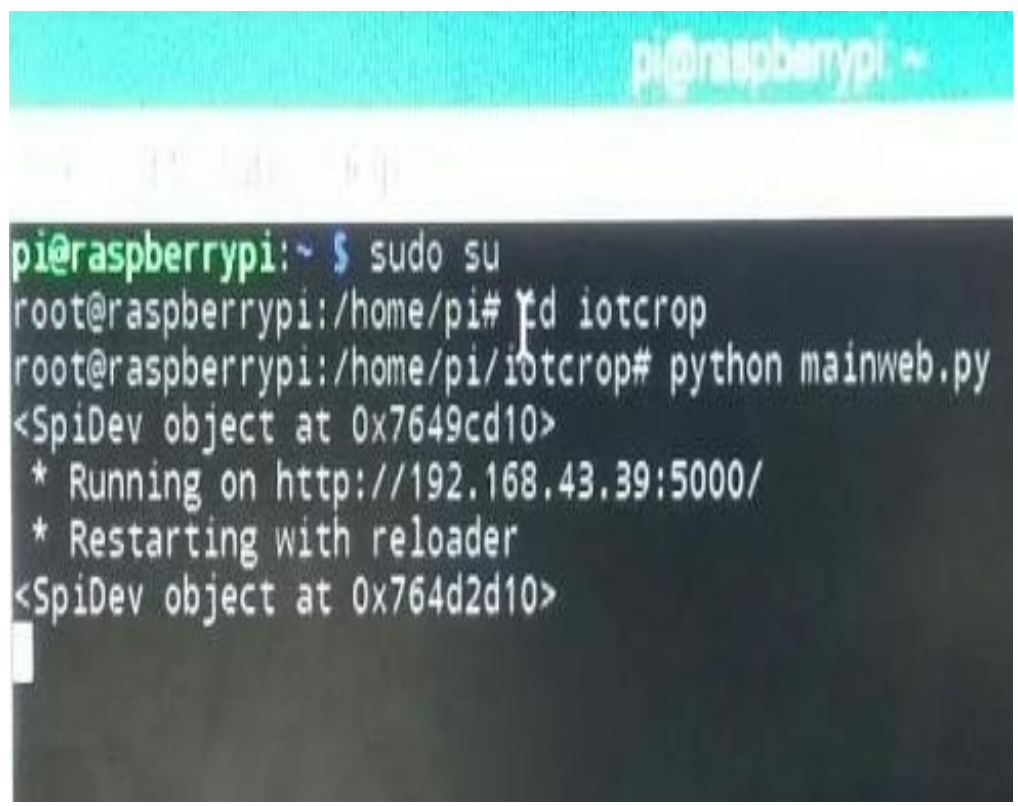

Fig.8. Login Page on Monitor 
After login happens in monitor run the http IP address observed in figure 8, later it shows to click login in web app enter secured user id and password in page, the screen shot of login page shown in the figure 9.

\section{plant monitoring and watering system Login}

Fig.9. Screenshot of Login Page on Web App

The web page figure 10 shows the screen shot of various results like temperature, humidity, light intensity, moisture sensor results the condition of land either dry of wet and IR sensor shows any intruder entered or not.

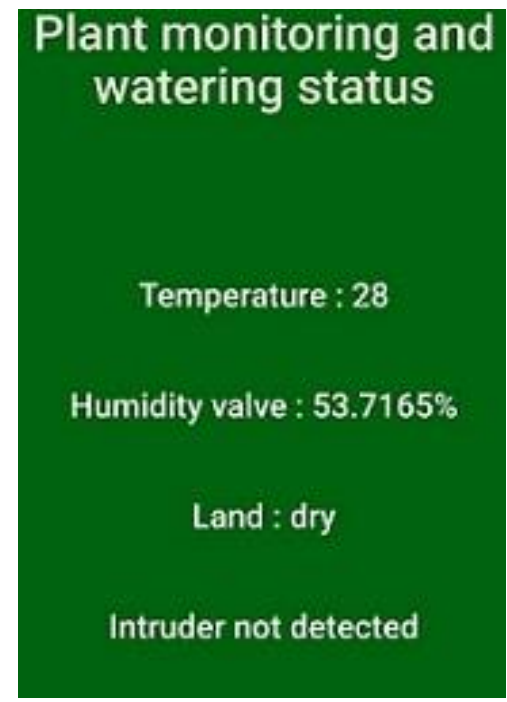

Fig.10. Screenshot of Monitored Results 
The continuous displays of results in the monitor are observed shown in the figure 11. In monitor results are observed continuously until system shutdown.

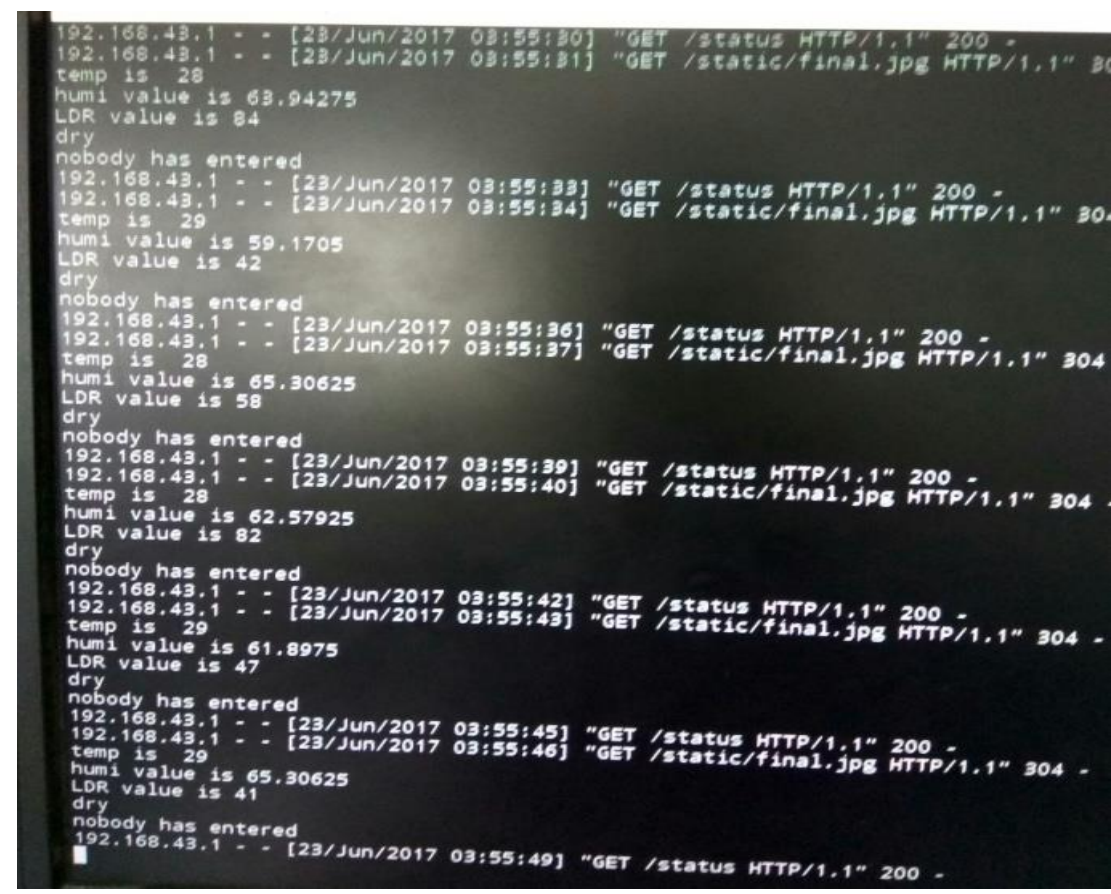

Fig.11. Display of Results in Monitor Screen

The figure 12 shows the screen shot on web app includes selecting motor operation either on or off. This helps in agriculture field when immediate motor operation takes place.

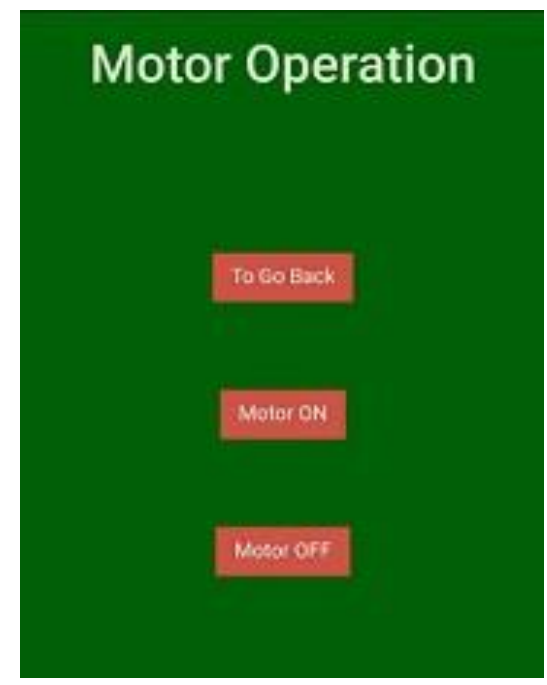

Fig.12. Screenshot of Motor Operation 
We note down the readings of temperature and humidity valve on hourly basis in order to check the valves which mainly consider for various applications example green house because some crops need less valves and some need more. The comparative of the actual to the measured is shown in figure 13 and 14.

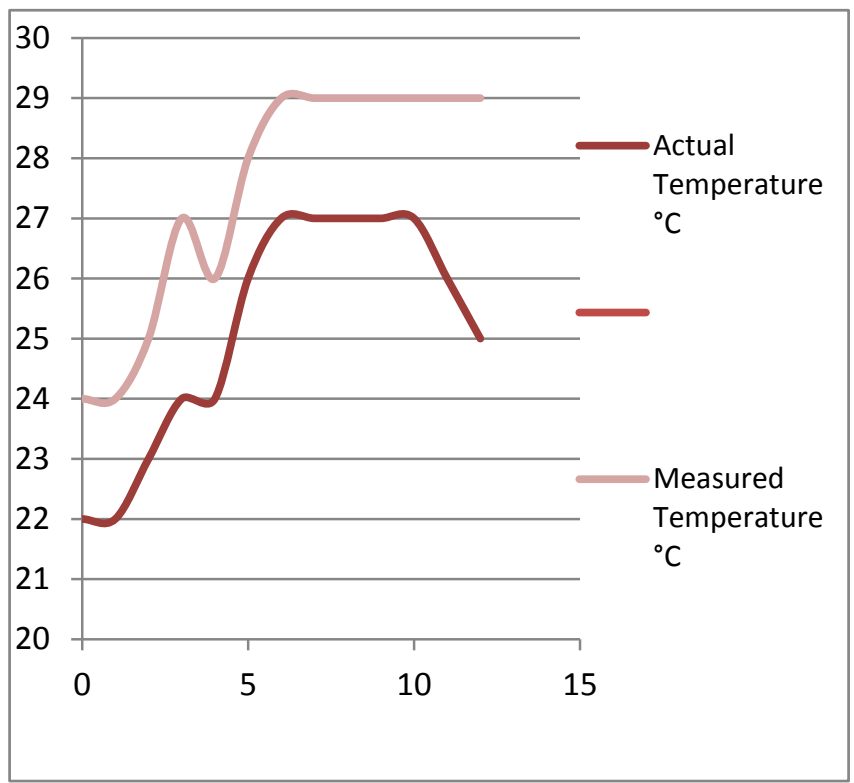

Fig.13. Graph of Temperature v/s Time

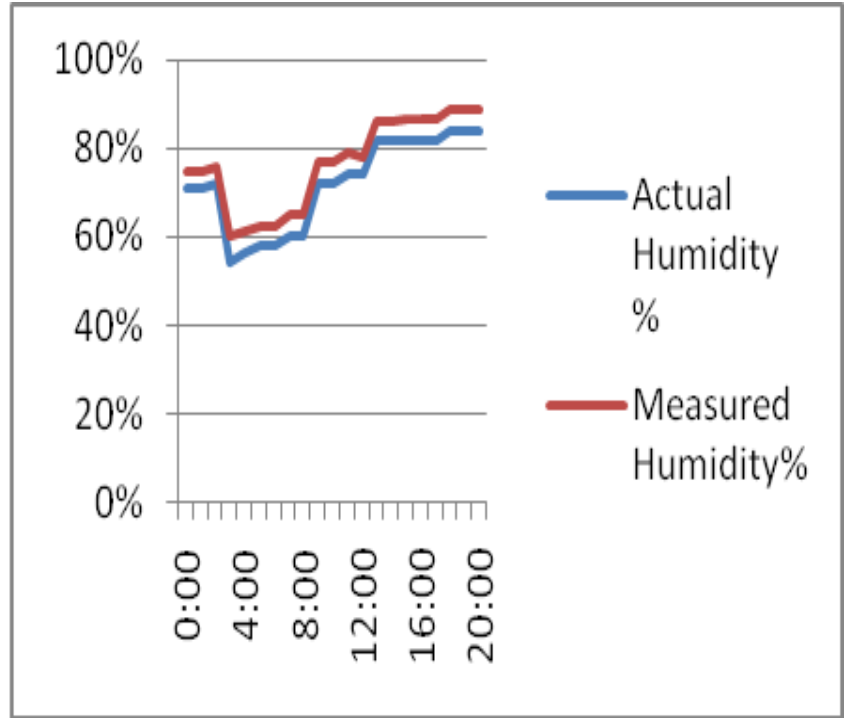

Fig.14. Graph of Humidity v/s Time 
Table 1 Comparisons between Existing and Proposed System

\begin{tabular}{|ll|c|c|}
\hline \multicolumn{1}{|c|}{ Parameter } & Existing system & Proposed system \\
\hline 1. & Processor/controller & Microcontroller [4],[7] & Raspberry pi \\
2. Sensors & $\begin{array}{c}\text { Moisture, temperature, humidity[1],[4],[7] } \\
\text { Wireless sensor network, IOT[1][2] } \\
\text { 3. Technology }\end{array}$ & $\begin{array}{c}\text { Moisture temperature, humidity, } \\
\text { LDR,IR }\end{array}$ \\
4. Web app & Developed[3],[8],[10] & IoT \\
5. Safety and security & Less secured & Developed \\
6. Accessibility & Only user can access[8] & More secured \\
7. & Result view & Represented in graphs, statements, \\
& & simulator, numeric valves [2][14] & All can access with IP address \\
\hline
\end{tabular}

The comparative study of existing systems with the proposed system is present in Table 1 . In the existing systems, developers considered old processor/controller with less storage memory, lack of technology usage, less number of sensors and applicable to the few applications. In our proposed system we considered novel concept IoT, Raspberry Pi processor, different sensors and representation of results in both numeric and statements.

\section{Conclusion and Future Scope}

The concept of IoT technology used to connect devices for collecting information. Improvements in agriculture for rural and urban areas are rising in recent decades with the help of digital technology. Presently available sensors are used to get possible outcome. The server based web app is developed which is free anytime and anywhere when system has connection with internet. This system will optimize the resources in plant area. The installation cost is tolerable as compared to large instruments. Totally this proposed system solves major issues of the agriculture field.

In future work, improvement in various agricultural applications will be done and how to do rain water harvesting in the agriculture field.

\section{Acknowledgements}

The authors thank the Principal, Professors and all technical staffs in Department of Electronics and Communication, Sri Jayachamarajendra College of Engineering, Mysuru, Karnataka, India for their support in completing this project.

\section{References}

[1] Joaquin Gutierez, Juan Francisco viva-medina, Alejandra Nieto-Garibay,and Miquel Angel portaGandara "Automated Iriigation System using a Wireless sensor Network and GPRS Module", IEEE Transactions on Instrumentation and measurement,Vol.63,No.1,January 2014.

[2] Kaushik Bhagawati, Rupankar Bhagawati and Doni Jini ICAR Research Complex for NEH Region, Arunachal Pradesh Centre, Basar-791101, India.'Intelligence and its Application in Agriculture: 
Techniques to Deal with Variations and Uncertainties", I.J. Intelligent Systems and Applications, 2016, 9, 56-61. Published Online September 2016 in MECS (http://www.mecs-press.org/) DOI: 10.5815/ijisa.2016.09.07

[3] Ibrahim Mat, Mohamed Rawidean Mohd Kassim, Ahmad Nizar Harun, Ismail Mat Yusoff MIMOS, Ministry of Science, Technology and Innovation, Kuala Lumpur, MALAYSIA, "IoT in Precision Agruculture applications Using Wireless Mositure Network" IEEE 2016 Conference on open systems(ICOS),October 10-12,2016,Langkawi,Malaysia.

[4] Tanmay Baranwal, Nitika, Pushpendra kumar Pateriya, Department of Computer Science, Lovely professional university, phagwara, Punjab.”Development of IoT based Smart Security and Monitoring Devices for Agriculture".978-1-4673-8203-8/16/\$31.00 @2016 IEEE.

[5] Mohamed Rawidean Mohd Kassim, Ibrahim Mat Ahmad Nizar Harun MIMOS, Ministry of Science, Technology and Innovation Kuala Lumpur, MALAYSIA.”Wireless Sensor Network in Precision Agriculture Application". 978-1-4799-4383-8/14/\$31.00@2014 IEEE.

[6] Kerry Taylor, Colin Griffith, Laurent Lefort, Raj Gaire, Michael Compton, and Tim Wark, CSIRO David Lamb, Greg Falzon, and Mark Trotter, University of New England, New South Wales "Farming the web of things" IEEE INTELLIGENT SYSTEMS on 2013.

[7] Shruti A Jaishetty, Rekha patil M.Tech department of computer science and engineering, poojya doddappa appa college of engg, kalaburgi ,Karnataka "IOT sensor approach network based approach for agricultural field monitoring and control",Journel of Research in Engineering and technology, vol-05 issue 06 June 2016.

[8] Silke migdall, Philipp Klug, Denis, Heike Bach VISTA Remote Sensing in Geosciences GmbH, Gabelsbergerstr.51, 80333 Munchen, Germany. University of Leige,water, environment and development unit, arlon campus environment Belgium "the additional valve of hyper spectral data for smart farming”@2012, IEEE.

[9] Gao Junxiang, Du Haiqing, School of science Huazhang agriculture university, Wuhan 430070,china , school of information and communication engineering Beijing university of posts and telecommunication, 100876, China" Design of green house surveillance system based on embedded web server technology" procedia engineering 23(2011 374-379).

[10] Tusher H.Gore, Mayuri p.kote,parameshwari B. varpe, Prof. M.T.Jagtap BE computer PVG COE Nausik, Maharashtra,HOD computer PVG COE Nausik, Maharashtra "Crop monitoring Analysis and controlling system", Journal of Advanced research in computer science and software engineering, volume-6, issue 2, February 2016.

[11] Zhao Liqiang, yin shouyi, Liu Leibo, Zhang Zhen, Wei shaojun "A crop monitoring system based on wireless sensor network" 1878-0296 ( 2011 published by Elsevier Ltd.

[12] Keerthi.V. V. V, Dr. G.N.Kodandaramaiah, Department of embedded systems, kuppam engineering college, JNT University, AP, Department of ECE ,kuppam engineering college, JNT University, AP. "cloud IoT Based Greenhouse monitoring system" Journal of Engineering Research and Applications, vol.5, issue 10,(part-3) October 2015.

[13] Purnima, S.R.N.Reddy, PhD "Design of Remote monitoring system with automatic irrigation system using GSM-Bluetooth” Journal of computer applications, vol 47-No.12, June 2012.

[14] Shwetha S. Patil, Ashwini V. Malviya "agricultural field monitoring system using ARM" Journal of advanced research in electrical, electronics and instrumentation engineering, Vol-3, issue 4, April 2014.

[15] Kirankumar Y.Bendigeri, Jayashree D.Mallapur "Advanced remote monitoring of a crop in agriculture using wireless sensor network topologies", Journal of electronics and communication engineering and technology, Volume 6, Issue 9, Sep 2015, pp. 30-38.

[16] Vipin k yedewar, Supriya. N. Kokate, prof.Mayur D.Ghatole "Review on crop monitoring system using GSM Technology", Journal of Engineering and technology, vol 04 issue 01 Jan 2017.

[17] Jaideep Kaur, Kamaljit Kaur "Internet of Things: A Review on Technologies, Architecture, Challenges, Applications, and Future Trends". I. J. Computer Network and Information Security, 2017, 4, 57-70 
Published Online April 2017 in MECS (http://www.mecs-press.org/) DOI: 10.5815/ijcnis.2017.04.07.

[18] www.internetofthings.com.

[19] www.Raspberrypi.org.

[20] www.sensors.com.

\section{Authors' Profiles}

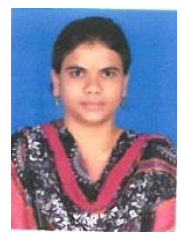

Anusha K. received her BE Degree in Electronics and Communication from VTU, Belgaum, Karnataka, India, in the year 2015. She completed M.Tech degree in VLSI Design and Embedded Systems at Sri Jayachamarajendra College of Engineering Mysuru, Karnataka, India in the year 2017. Her topics of interests are in VLSI Design and Embedded Systems.

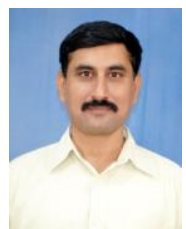

Dr. U. B. Mahadevaswamy has completed his BE degree in electronics and communication in the year 1988 from University of Mysuru, M.Tech in industrial electronics in the year 1995 from Mangalore University and obtained $\mathrm{PhD}$ in electronics from University of Mysuru in the year 2013. He is presently working as Associate professor in the department of electronics and communication of Sri Jayachamarajendra College of Engineering, Mysuru, and Karnataka, India. He has authored several textbooks and published many technical and research papers in international journals and conferences. His research interest includes the topics, wireless sensors networks, VLSI design, embedded systems and digital signal processing.

How to cite this paper: Anusha k, U B Mahadevaswamy,"Automatic IoT Based Plant Monitoring and Watering System using Raspberry Pi", International Journal of Engineering and Manufacturing(IJEM), Vol.8, No.6, pp.55-67, 2018.DOI: 10.5815/ijem.2018.06.05 